\title{
Overcoming barriers to health care access for medically underserved children
}

Irwin Redlener, $M D$, FAAP

Associate Professor of Pediatrics

Albert Einstein College of Medicine

Chief

Division of Community Pediatrics

Montefiore Medical Center-Albert Einstein

College of Medicine

Bronx, New York

President

The Children's Health Fund

New York, New York
GOR MLUONS OF American children, - regular access to high-quality primary health care is a complex and intimidating challenge. As many as 10 million children have no health insurance, and millions of others are only partially covered. However, fiscal accessibility is not the only barrier.

The federal government recognizes more than 2,000 health personnel shortage areas (HPSAs) where the problems are not lack of health insurance, but lack of reasonable logistic access to primary health care providers (FederalRegister, 1991). The shortage areas have less than one health provider for every 3,000 people. The population experiencing these resource distribution and logistic barriers include millions of families and children. Furthermore, there are a number of special child populations experiencing specific barriers to care related to social, economic, or geographic conditions. These populations include children of migrant farmworkers, certain Native American tribes, and homeless children. All may be unable to obtain regular health care in a setting or according to a schedule that is compatible with current standards of child health care. 


\section{MEDICALLY UNDERSERVED CHILDREN}

An important aspect of understanding and managing access to care problems is definitional. In developing countries, large numbers of children may have an absolute lack of access; there simply are no resources available, including emergency or life-saving services. This extreme resource deprivation is rarely seen in the United States or in other industrialized countries. In this country, most children, including those in geographically remote areas or those who live in extreme poverty, will be able to receive emergency medical attention.

Medically underserved American children are likely to experience care that is delayed, fragmented, and episodic. Care is more likely to be obtained only when medical problems are acute and readily apparent. It is much less likely to be received for chronic problems, anticipatory guidance, preventive or screening interventions, and other reasons included under the umbrella of good primary care for children. Such standards of care have long been recognized and described by professional organizations such as the American Academy of Pediatrics (Kutnik, 1991). The defining principles of adequate care for children include continuity, comprehensiveness, and case management. Pediatricians often refer to services that meet these criteria as a "medical home," and few would disagree with the notion that all children deserve such care.

When a medical home is not available, continuity suffers. There is no single place where the child, his or her family, and the medical history are known. Immunization rates tend to be low and care highly disorganized. This situation is commonplace for severely disadvantaged populations. In recent years, with rising underemployment and decreasing health insurance coverage, more and more children do not have an identified continuity-based health resource.

Homeless children are a particularly highrisk population from the perspective of access to primary care. In large cities, the problem is both visible and resistant to easy solutions. The New York Children's̀ Health Project (NYCHP), developed in 1986 and 1987 , focuses on medically underserved homeless children in the city's shelter system. These children are not only severely disadvantaged but regularly experience significant barriers to access to appropriate sources of primary care.

\section{HOMELESS CHILDREN IN NEW YORK CITY}

Homelessness has been a serious and growing problem in many urban areas since the early 1980 s. A severe reduction in public housing stock, coupled with a high demand for subsidized apartments, has created a crisis that is painfully apparent in New York City. More than 200,000 families await assignment to public housing units as they become available. According to a 1987 study more than 100,000 families were living doubled- and tripled-up (The Select Committee on the Homeless of the City Council of New York, 1987). As many as 5,200 families, including about 12,000 children, are homeless on any given night. Over the course of a year, 20,000 to 25,000 children are officially identified as homeless.

When a family in New York City becomes homeless, they enter a complex system of transitional shelter. The system includes shortstay hotels; longer-stay, privately owned welfare hotels; and agency-run family shelters. The average length of stay in the shelter system has varied since 1985 from about 4 months to over 15 months. In early 1992, the average length of stay in the homeless shelter 
system was 7 to 9 months and climbing steadily (Human Resources Administration of the City of New York, 1992).

Most families entering the system areplaced in shelters far from their original neighborhoods, often in another borough. Their connections to educational, social, and health services are severed abruptly. Conditions in the shelters-especially in the welfare hotels-are often squalid and dangerous. Violence, drugs, and prostitution are frequently rampant. Shelter conditions include exposure to lead, lack of refrigeration or cooking facilities, vermin, and overcrowding, Such conditions predispose children to numerous health problems.

It should also be noted that while most homeless children reside with their mothers, many are "unattached," that is, on their own without a parent or guardian. Unattached children include the 10,000 or more runaway youth who come through New York City every year and the several thousand children in the foster care system who are considered "unplaceable." The NYCHP cares for some children in both groups.

Making matters all the more challenging is the reality of insufficient public sector health services for all children in New York City. When children find themselves in a new neighborhood under circumstances precipitated by poverty and homelessness, it is extremely difficult to identify anything approaching the concept of a medical home. As a result of their increased health risk and diminished access to primary care, homeless children have serious health problems ranging from underimmunization to poorly controlled chronic conditions. A study of 650 children experiencing their first encounter with NYCHP between mid-January and midFebruary 1992 found:

- only one-third had up-to-date immunizations;
- $28 \%$ had asthma;

- $47 \%$ had had otitis media within the last 18 months; and

- $19 \%$ had anemia (Redlener, 1992). Thirty-two percent had been to a hospital emergency department, and $6 \%$ had been hospital inpatients within 3 months of their first visit to the NYCHP (Redlener, 1992). In total, only $9 \%$ of new patients had been seen by a private physician compared with $62 \%$ of new patients who had been receiving hospital-based services.

\section{THE NEW YORK CHILDREN'S HEALTH PROJECT}

The NYCHP began operations in November 1987 after a one-year planning period. It is operated under the auspices of the division of Community Pediatrics at the Montefiore Medical Center-Albert Einstein College of Medicine. The program was created in response to a growing concern that homeless children in New York City were not receiving regular medical services and that, as a result, their health status was seriously compromised.

The NYCHP, headquartered in midtown Manhattan, usesthreecustom-designed, wellappointed, 33-foot-long mobile medical units (MMUs), each containing two examination rooms, a waiting area, laboratory space, a small procedures room, and space for patient registration. The MMUs visit 15 sites sheltering homeless families in four of New York City's boroughs (not including Staten

Homeless children have serious health problems ranging from underimmunization to poorly controlled chronic conditions. 
Island) each week. All sites are visited on a regular schedule, and the same provider team goes to the same locations to encouragelong-term relationshipsbetween the families and the provider teams.

MMU teams consist of a board-certified pediatrician, a second provider (either another pediatrician, a nurse practitioner, or a pediatrician-in-training), a nurse, a registrar, and a driver who also serves as the logistics coordinator. All pediatricians are full-time members of the faculty and staff of the Albert Einstein College of Medicine and the Montefiore Medical Center.

Sites are chosen in collaboration with the city and the voluntary agencies responsible for their operation. Most sites are welfare hotels or agency-run family shelters. Approximately 230 children are seen on the three MMUls each week. No fees are charged, and Medicaid is billed for eligible children.

\section{RANGE OF SERVICES}

In $1991,4,224$ children were seen for a total of 15,326 encounters or, on average, 3.6 encounters per child. Because a project goal is to provide a medical home for each of its patients, the MMUls provide full primary care. This care includes all aspects of wellchild care (screening; scheduled health assessments: immunizations; growth, development, and behavioral monitoring; anticipatory guidance; and prevention education), the management of acute illnesses, and the management or coordination of chronic conditions.

Because the NYCHP patient population is indigent, without permanent address, and without service ties in the communities in which they are sheltered, maintaining a true medical home is a challenging task. Program design overcomes or ameliorates many obstacles that interfere with optimal delivery of services. The objectives of the NYCHP's pri- mary health care delivery system include comprehensive care, continuity of care, adequate medical records and patient tracking, primary care follow-up, and case management and gatekeeping functions.

\section{Comprehensive care}

The NYCHP diagnoses and treats acute illnesses the same way any pediatrician's office or pediatric clinic does. Chronic conditions such as asthma, anemia, and atopic dermatitis are managed by regular visits and appropriate laboratory tests. Extensive wellchild care is also provided in accord with the standards set by the American Academy of Pediatrics (Kutnik, 1991). Complete family and personal histories are obtained including social as well as medical information. Physical examinations and laboratory screening are also performed on a regular schedule.

Team members provide anticipatory guidance dealing in such areas as parenting, child safety, and behavioral management. The NYCHP is able to refer families that need additional help to a staff psychologist at projectheadquarters, ratherthan on the MMU.

A significant effort is made to educate parents regarding child health and parenting issues including the value of ongoing primary care. All members of the primary care team participate in the educational process. In addition, the NYCHP conducts a formalhealth education course for parents and older children. The NYCHP has also organized a substance abuse prevention program for preadolescents and adolescents.

\section{Continuity of care}

Continuity is particularly difficult for the NYCHP patient population because families may be quickly moved between shelters and because the MMU visits each location only once a week. Patients can, however, depend on the team being at the prescribed site at the regular time each week. In addition, the 
teams tend to be stable, and, over time, families gain familiarity with and trust in their team.

Families are reminded repeatedly that health care is available to them at any time. All patients are given a 24-hour telephone number that is answered by a service that refers the call to an on-call provider. Although it is not feasible to see most late-night clinical patients, referrals are made to appropriate emergency facilities. The referring NYCHP providers request follow-up information from the emergency providers.

\section{Adequate medical records and patient tracking}

The NYCHP's innovative medical record system helps ensure clinical tracking as well as continuity of medical services. All patient records are maintained by a computerized system designed by the NYCHP and John Snow, Incorporated (Boston, Massachusetts). This system allows the clinical team to view and print out relevant information on any patient ever seen by the program. This feature is particularly helpful for the family that has moved repeatedly from one shelter to another.

Encounter forms are completed by providers and other clinical staff on the MMU and are brought back to headquarters at the end of each day. The following day, a data team enters the previous day's encounter information into the central database. Twice each week, the database is downloaded to personal computers on each of the MMUs: Each MMU also has a portable printer.

\section{Primary care follow-up}

The NYCHP makes a concerted effort to help families meet the regular schedule of recommended child health maintenance visits as well as return for follow-up of acute problems. If a child is not brought in for a scheduled visit, a series of steps is taken
Because homeless children have had limited access to appropriate pediatric care, there is a substantial backlog of unmet secondary and tertiary medical needs.

including letters and telephone calls to the family and coordination with public sector social service staff. At least 5,000 letters are sent to patients each year.

\section{Case management and gatekeeping functions}

The NYCHP is committed to broad-based case management with a particular emphasis on follow-up for specialty and subspecialty service needs. The NYCHP plays a gatekeeper role to facilitate access to these extended secondary and tertiary health services. In addition, attention is given to nonmedical needs such as housing and educational attachments.

Because homeless children have had limited access to appropriate pediatric care, there is a substantial backlog of unmet secondary and tertiary medical needs. NYCHP staff regularly uncover previously undiagnosed congenital problems. Likewise as a result of a long history of access barriers, acute diseases tend to become chronic (e.g., poorly managed or nonmanaged otitis media leads to chronic otitis and hearing loss), and many chronic conditions such as asthma may be out of control. As a consequence, the referral rate is quite high. While a rate of 1 specialty or subspecialty service referral is expected for every 55 to 60 patient encounters in a typical pediatric practice, approximately 1 in 14 NYCHP health visits results in a referral (Contemporary Pediatrics, 1988).

In fact, some 800 to 1,000 referrals are made by NYCHP primary care teams each year, necessitating approximately 3,000 
separate appointments. Since 1988, the specialty referral process has been developed as a discrete activity within the overall program. A nurse specialist coordinates this component, which includes four additional staff members based at program headquarters and one based at the main referral hospital.

Because homeless families in the shelter system are attempting to manage a large and complex set of survival challenges, compliance with appointments for non-life-threatening medical conditions tends to be limited. Furthermore, the financial and logistic resources necessary to get to the referral resource are also severely limited. Consequently, before the introduction of the current, resource-intensive follow-up program, compliance with specialty referrals was no more than $5 \%$ to $10 \%$ for all appointments made by the primary care team. Since introduction of the team, more than $70 \%$ of appointments are either kept or rescheduled through the family's initiative.

\section{INSTITUTIONAL CONTEXT AND FISCAL SUPPORT}

The NYCHP is a major clinical program of the division of Community Pediatrics at the Montefiore Medical Center-Albert Einstein College of Medicine (Bronx, New York). The program's co-founder is chief of the division. The program is also supported by a recently created not-for-profit, tax-exempt foundation, The Children's Health Fund (CHF).

The 1992 NYCHP budget is approximately $\$ 2.5$ million. Medicaid reimbursement at the hospital-negotiated rate yields approximately $\$ 0.7$ million each year, and another \$0.7 million comes to the hospital from a federal grant under the Stewart B. McKinney Homeless Assistance Act (Public Health Service Act, § 340). The CHF raises philanthropic support, mostly from the private sector, to cover the special access-enhancing activities described above.

\section{THE NYCHP AS A NATIONAL MODEL: WHY MOBILE-BASED CARE?}

Although the NYCHP is one of the largest mobile-based primary pediatric care programs in the country, it is clear that mobile health care only has a limited role in solving the access problems of medically underserved populations. As noted throughout this article, intensive utilization of resources and a substantial amount of creative program planning are required to meet the program's goal of providing a medical home to profoundly underserved children. Yet the experience of the NYCHP shows that it can be accomplished, in spite of the severe challenges associated with any particular population.

Currently, millions of American children are experiencing great difficulty in accessing regular primary care for a wide range of fiscal and nonfiscal reasons. For geographically stable populations, solutions other than mobile medical units would be more appropriate and cost-effective. Extending services at existing health centers or ambulatory facilities, opening neighborhood-based comprehensive child health clinics, and developing transportation systems to bring children to existing facilities are all potentially viable options that should be explored.

It is very difficult, however, to assure public sector support to meet child health needs by traditional means in many urban and rural HPSAs. Increased demand for services at a time of shrinking local and state budgets makes it unlikely that sufficient funds will be identified to make such options widely available. Therefore, special initiatives, such as the NYCHP, must continue to meet the health care needs of special populations experiencing particular barriers in identifying a regular source of primary care. 


\section{REPLICATING THE MODEL}

Through the efforts of the CHF, the NYCHP has become an effective and transferable model. The fund makes start-up grants, including providing a fully equipped $\mathrm{MMU}$, to selected communities requesting such support. Successful applicants must demonstrate the existence of a significantly medically underserved, indigent population as well as provide evidence that the target population cannot obtain primary care at a traditional site. New programs are always started under the auspices of a department of pediatrics at a major medical center. In rural areas where this is not possible, grants have been made to community health centers that have collaborative relationships with the medical centers closest to them.

In all cases, funded programs become part of a national network of projects using the same database and capable of pooling clinical data. No program will be supported that does not ascribe to the basic principles of comprehensive and continuous primary care services. Programs emphasizing screening, isolated categorical initiatives (e.g., "immunization drives"), and other episodic activities are not funded.

The NYCHP was designed to serve the special needs of medically underserved, extremely disadvantaged children in New York City. As a model, and as the flagship program of a national network, the NYCHP demonstrates that it is possible to provide a medical home for children in a variety of challenging situations where access to traditional providers is limited.

It is clear, however, that mobile units or other creative ways to overcome barriers to access to care are an insufficient long-term answer. Ultimately, the public sector must take steps to ensure that all American children have regular access to a true medical home regardless of their social or economic situation. In the interim, special initiatives such as the NYCHP must continue to fill the gap.

\section{REFERENCES}

Contemporary Pediatrics. (1988). The pattern of pediatric referrals. Contemporary Pedialrics, 5, 20-30.

Federal Register. (1991). List of designated primary medical care health professional shortage areas (HPSAs); List of withdrawals from primary medical care HPSA designation. Federal Register, 56(188), 49,250-49,342.

Human Resources Administration of the City of New York. (1992). Emergency housing services for homeless families: Monthly reports. New York, NY: Author.
Kutnik, L. (Ed.). (1991). Management of pediatric practice. (2nd ed.). Elk Grove Village, IL: American Academy of Pediatrics.

Redlener, l. (1991). New York Children's Health Project. Unpublished study.

The Select Committee on the Homeless of the City Council of New York. (1987, January 20). Report on the horneless crisis. New York, NY: Author. 
Aday, L.A.,Fleming, G.V., E Anderson, R. (1984). Access to medical care in the U.S.: Who has it, who doesn't? Chicago, IL: Pluribus Press.

Alperstein, G., Rappoport, C., \& Flanigan, J. (1988). Health problems of homeless children in New York City. American Joumal of Public Health, 78, 1232-1233.

Bassuk, E.L., \& Rubin, L. (1987). Homeless children: A neglected population. American Joumal of Orthopsychiatry, 57, 279.

Bassuk, E.L., \& Rosenberg, L. (1990). The psychosocial aspects of homeless and housed children. Pediatrics, 85, 257-261.

Brellochs, C., \& Carter, A.B. (1990). Building primary health care services in New York City's low income communities. New York, NY: The Community Service Society.

Gallagher, G.E. (1986). No place like home: A report on the tragedy of homeless children and their families in Massachusetts. Boston, MA: The Massachusetts Committee for Children and Youth.
Kaspar, J.K. (1987). The importance of type of usual source of care for children's physician access and expenditures. Medical Care, 25, 386-398.

Miller, D.S., E. Lin, E.B.H. (1988). Children in sheltered homeless families: Reported health status and use of health services. Pediatrics, 81, 668-673.

Newacheck, P.W., \& Halfon, N. (1986). Access to ambulatory care services for economically disadvantaged children. Pediatrics, 78, 813819.

Shedlin, M. G. (1989). The health care of homeless mothers and children: Impact of a welfare hotel. New York, NY: Medical and Health Research Association of New York City.

U.S. Conference of Mayors. (1987, May). A status report on homeless families in America's cities: A 29 city survey. Washington, DC: Author. 